\title{
Astronomers silenced in star-name wars
}

\section{William Triplett, Washington}

Laurent Pellerin is an angry astronomer. After publicly criticizing one of several organizations that sell individuals the 'right' to name stars, he has been told to shut up by his planetarium employer.

The reason, according to an item in the August issue of Sky \& Telescope magazine, was that the company - the Illinois-based International Star Registry (ISR) - had threatened Seminole Community College Planetarium in Sanford, Florida, with a defamation lawsuit over Pellerin's remarks, which were broadcast by a local radio station.

Pellerin says he was "only trying to educate the public" to facts that many such companies either play down or do not mention. In particular, when people pay such companies from about $\$ 50$ for a certificate conferring the chosen name - often in memory of a dead relative - on a specific star, this has no standing among professional astronomers.

After sending a certificate to the buyer, ISR enters the star's name and coordinates in a book that it publishes. "Because these star names are copyrighted with their telescopic coordinates in the book," ISR's web page claims, "future generations may identify the star name in the directory and, using a telescope, locate the actual star in the sky."

But Bob Milkey, the executive officer of the American Astronomical Society (AAS), says he knows of "no astronomers who look at the ISR catalogue of star names". Despite this, it is not uncommon for visitors to observatories to ask to see 'their' stars.

"One guy came in looking for the star he'd 'named' for his girlfriend," says Robert Martino, assistant director of Perkins Observatory at Ohio Wesleyan University. "I told him there was no star by that name."

The International Astronomical Union is officially the sole designator of stars, typically identified by numbers. When people find that out, Pellerin says, they "can feel as if they've lost their loved one all over again".

Two years ago the New York City Department of Consumer Affairs cited ISR for "engaging in a deceptive trade practice". But ISR has refused to pay the resulting fine of $\$ 3,500$ imposed by the city, arguing, according to Rocky Mosele, ISR's vice-president and director of marketing, that "we have never been found in violation of any laws".

ISR has also threatened legal action against at least two other astronomers besides Pellerin over public criticisms. John Martin, a graduate student at Case Western Reserve University, had posted a critical note about ISR on his personal website. "I do a lot of outreach," Martin says, "and I get a lot of questions on this subject. It was meant to be informative."

An ISR lawyer did not see it that way, sending Martin and the university a letter of

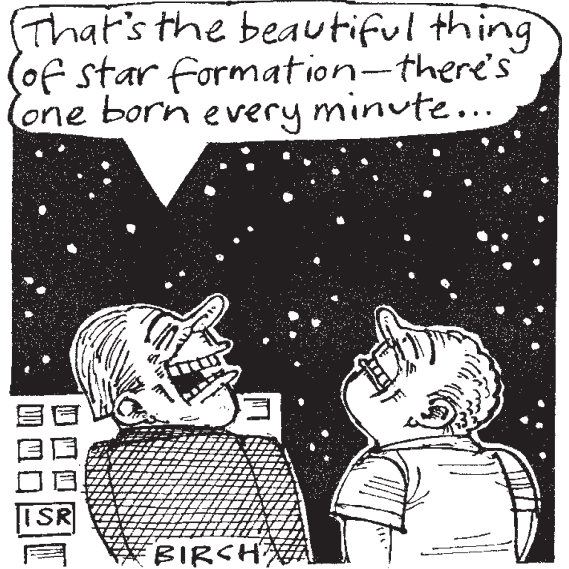

objection. Martin deleted the note before the university became involved.

Ohio Wesleyan did get involved — much to Martino's unhappiness. Martino had posted a note on the Perkins Observatory website denouncing star-selling. ISR attorneys threatened to sue not only Martino, but also the observatory and the university if the material were not removed.

Martino claims that the university decided to comply even though it was confident of winning in court. "They gave in because it was cheaper than fighting," he says. But Pam Besel, director of public relations at Ohio Wesleyan University, says administrators ordered Martino to remove the note because "his views are not necessarily the university's".

Pellerin says that senior officials at the Seminole Community College told him not to discuss ISR with anyone. He was later given a copy of a letter from the university to ISR stating that, although the college's legal department did not believe Pellerin's remarks to be defamatory under Florida law, employees would no longer be talking about ISR. Tom O'Hern, who handles legal matters for the college, declined to comment.

At the AAS, Milkey says he gets "a few" inquiries from people every year asking for advice about buying a star-name."We're generally very careful in what we say," he notes. "I tell them that it has no standing in the scientific community, that astronomers only recognize IAU designations, but if they want to go ahead and buy it as a novelty, then go ahead."

Others see more at stake."This is a clear-cut case of academic freedom," says Steve Shore, chairman of the department of physics and astronomy at Indiana University, South Bend.

Mosele is unrepentant. He confirms that ISR has sent letters to various astronomers and institutions threatening suits for defamation/libel. "What they were saying about us was wrong, and it's illegal to say those things," he says. "We were not trying to compromise their rights to free expression; we said to stop saying those things because they're not true."

"In a strict interpretation of the law these companies are not fraudulent," agrees one prominent astronomer who asks not to be identified. "If you pay them money, they'll send you something saying the star is yours; that's what they say they'll do, and they do it. But does the consumer really know what he's buying?"

\section{Berlin genome centre to go ahead}

Quirin Schiermeier, Munich

After a year of lobbying from local life scientists, the governments of Berlin, Potsdam and the surrounding state have agreed to create the Berlin and Brandenburg Genome Research Centre.

Plans for the centre were drawn up last year by Detlev Ganten, scientific director of the Max Delbrück Centre for Molecular Medicine, Hans Lehrach, director of the Max Planck Institute of Molecular Genetics, Lothar Willmitzer, director of the Max Planck Institute of Molecular Plant Physiology, and Günter Stock, head of research and development at the pharmaceutical company Schering.

Institutes in the region that do genome research will first commit themselves to a joint scientific strategy, linked to the regional biotechnology industry.

Eater2odlogthaomitlanstlagekineBetdin's three universities, the University of

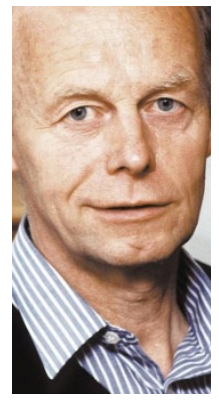

Ganten: helped draw up plans for the centre. bioinformatics, will then per year.

Parts of the 'virtual' genome network will be transferred to a genome centre, probably at the FU, in around 2003. It is designed to house about 150 scientists in $\mathbf{3 0}$ cross-institutional research groups. 